\title{
ON THE DEVELOPMENT OF THE BROWN SPIDER LOXOSCELES GAUCHO GERTSCH (ARANEAE, SICARIIDAE): THE NYMPHO-IMAGINAL PERIOD
}

\author{
Isabela M.P. Rinaldi ${ }^{1}$ \\ Luiz C. Forti ${ }^{2}$ \\ André A. Stropa ${ }^{1}$
}

\begin{abstract}
Observations of the developmental biology of Loxosceles gaucho Gertsch, 1967, the brown spider of southeastern Brazil are scarce. The present study reports the method of individualized rearing of 18 populations of L. gaucho, kept in laboratory under varied diet conditions, and characterizes their nympho-imaginal period as well as factors related to their reproduction. Females built the first egg sac about 20 days after copulation and nymphs hatched 40 days after the laying date. Average offspring was 61.3 spiderlings and females usually built three to four successive egg sacs in a period of five to seven months. First nymphs initiated their predatory activity between the $5^{\text {th }}$ and $8^{\text {th }}$ days after hatching and the majority reached adulthood within six moults (range of five to eight) in approximately 15 to 17 months (male) and 15.5 to 18 months (female). The average sex ratio equaled 1.0:1.7 (male:female). The wide individual variability of this species intermoult intervals is herewith expressed by the "intermoult rate", which was fairly uniform for both intra and interpopulations and gives a relevant aspect for a general idea of the life cycles of spiders.
\end{abstract}

KEY WORDS. Brown spider, Loxosceles gaucho, Sicariidae, development.

The sedentary weavers of Loxosceles Heineken \& Lowe, 1835 are widely distributed throughout South America, where 30 species are known (GERTSCH 1967). Although consistently responsible for accidents which result in severe damage to men and domestic animals, available biological data for South American species are restricted to the works of GALIANO (1967) and GALIANO \& HALL (1973) for L. laeta, and BÜCHERL (1961), who dealt with L. laeta and L. gaucho, naming them as rufipes and rufescens, respectively according to GERTSCH (1967). Regarding L. rufescens (= L. gaucho), BüCHERL (1961: 221) studied the number of eggs and the maternal care, presenting some data about the nymphal period, biometric data on egg sacs, eggs and $1^{\text {st }}$ larvae.

The brown spider Loxosceles gaucho is a species from southeastern Brazil, abundant in the region of Botucatu, State of São Paulo, and has been reared in the Departamento de Zoologia, Universidade Estadual Paulista (UNESP), Campus de

1) Departamento de Zoologia, Instituto de Biociências, Universidade Estadual Paulista. Caixa Postal 510, 18618-000 Botucatu, São Paulo, Brasil.

2) Departamento de Defesa Fitossanitária, Faculdade de Ciências Agranômicas, Universidade Estadual Paulista. Caixa Postal 237, 18603-970 Botucatu, Säo Paulo, Brasil. 
Botucatu, during the last six years. Among the four phases of life cycle in Araneae (VACHON 1957; FoeliX 1982; SHAEFER in NENTWIG 1987), the definition of the nympho-imaginal period of $L$. gaucho is fundamental to subsidize any control program, as it comprehends the phase in which spiders of the first instar hatch from the egg sac and begin the course of their upgrowth toward maturity. The purpose of this work is to characterize this particular period in L. gaucho, taking into account different populations and factors related to their reproduction.

\section{MATERIALS AND METHODS}

\section{Characteristics of the spiders collect sites}

Spiders were collected in distinct habitats of the Botucatu region, São Paulo State: a) under rocks or gravel and between tiles and stacked planks, associated to Gryllus sp., Camponotus sp., Dictyoptera, Isopoda, Diplopoda, Discocyrtus invalidus Piza, 1938 (Opiliones) and Scytodes sp. (Araneae, Scytodidae); b) under abandoned sleepers across railway tracks, always restricted to areas free of vegetation, sharing the same territory with Camponotus rufipes (Fabricius, 1775) (Formicidae) yet apparently exhibiting no trophic relation with them; c) sheltered in cardboard boxes, behind pieces of furniture and in wooden boxes stacked in internal and external areas of the UNESP buildings (district of Rubião Júnior).

\section{Rearing the spiders in captivity}

The laboratory is equipped with air conditioning and there is a monitoring of temperature and relative air humidity by a thermohydrograph. During the experiment the average temperature was of $25.9^{\circ} \mathrm{C}$ (maximum and minimum values respectively of $31.2^{\circ} \mathrm{C}$ and $21.1^{\circ} \mathrm{C}$ ), and the average humidity was of $63.7 \%($ maximum and minimum values respectively of $73.4 \%$ and $42.8 \%$ ). The luminosity was controlled by a Coel RT 30 type programmer which provided $67 \%$ photoperiod ( 16 hours a day of darkness). From the time of their emergence from the egg sacs, which were built in the laboratory, the spiderlings were individualized in culture tubes covered with moisture cotton. Spiders of the $4^{\text {th }}$ instar were transferred to plastic boxes $(17 \times 7.5 \times 7.5 \mathrm{~cm})$ with air-holes covered with nylon mesh, and containing moisture cotton inside.

\section{Feeding methods}

Varying the diet, as supported by LOWRIE (1987), a weekly feeding program was followed, which consisted of offering to instars I to III about six Drosophila sp. or one grasshopper nymph. From the IV instar onwards, about six Musca domestica Linnaeus, 1758, or two to three Gryllus sp., or grasshoppers nymphs were offered. Previous tests to evaluate the food preferences of the older nymphs consisted of offering different food items easily kept in laboratory or proceedings from sweepings. The spiders (five groups about 40 individuals) fasted for five days and their preferences were estimated 24 hours after presentation of the prey. The spider's prey preferences in a decreasing order were: 1) adult Muscidae and Gryllus nymphs; 2) grasshoppers nymphs; 3) larvae of the wax moth Galleria mellonella Linnaeus, 1758, larvae of the darkling beetle Tenebrio molitor Linnaeus, 
1758 and nymphs of the termite Cornithermes cumulans Kollar, 1832. House flies and small cricket nymphs tangle themselves onto the spider's webs as they try to fight free and are immediately perceived and caught. The same does not occur with other preys, especially the nymphs of termite. The beetles larvae and the wax moth larvae were less suitable preys for the spiders. The beetles are heavily sclerotized and the wax moth are lucifugous, they took shelter in their silk cocoons and therefore were inaccessible preys for the spiders. To evaluate the first prey acceptance by the freshly hatched spiderlings, it was offered them Drosophila and the predation activity was estimated at two different times each day for nine populations of an average of 49 individuals each. The spiderlings showed $100 \%$ acceptance between the $5^{\text {th }}$ and $8^{\text {th }}$ day of life. Based on this observation, the $5^{\text {th }}$ day after hatching was adopted as the $1^{\mathrm{st}}$ feeding for the remaining spider populations.

\section{Records}

The hatching times, the number of molts until maturity, the duration of the stadia, and deaths were daily recorded for each developing spider. From the fifth instar onwards these records were carried out every two days. The nymphs hatched from each egg sac corresponded to the same with the viable eggs.

\section{RESULTS}

\section{Egg sacs and brood care}

The egg sacs have the shape of a convex flat disc and are covered with a white silk coating which has a cotton-like layer and a viscous consistency, whereas the innermost layer is smooth and yellowish. They measure about $2.0 \pm 0.6 \mathrm{~cm}$ total diameter and $1.0 \pm 0.5 \mathrm{~cm}$ diameter at the central disc, where the eggs - arranged as a pyramid - are concentrated. When the time for hatching approaches, a large extension of the cotton-like coating of the central disc disappears enabling the spiderlings to be seen. Females may or may not care for the egg sac and the same female may vary this habit in relation to their various egg sacs. The mother which takes care of the cocoon, remains on it, with its abdomen touching the central disc or sometimes only the female forelegs touching its edges.

\section{Female fertility: number of egg sacs and number of viable eggs}

The majority of adult females usually build more than one egg sac in laboratory. In 30 analyzed females during an average period of 6.5 months, $77 \%$ built more than one egg sac; and among these, $56.5 \%$ produced about three or four egg sacs. Six cocoons were built by a particular female after 286 days from the collect date, resulting 409 nymphs, and 154 days after the building of the $6^{\text {th }}$ egg sac, it was built the $7^{\text {th }}$, with only six spiderlings. The average number of nymphs per egg sac for $L$. gaucho was $61.3(\mathrm{~N}=78 \mathrm{egg}$ sacs). From this total, $43.6 \%$ of the egg sacs contained 60 or more spiderlings whilst $9 \%$ was of 100 or more. The highest number of descendants per egg sac was 117 and the lowest one was 25. Values below this number (from 12 to 1 ) were considered to be egg sacs of the senescent period and not reckoned in the average calculation. Females may accept copulation with various males, at least when they do not have egg sacs. In laboratory, cocoons 
occurred throughout the year. For 33 adult females, 22 layings were registered from November to April, six occurred between May and June, three between July and September, and two in October. Of 21 females, born and coupled in laboratory, $61 \%$ always produced egg sacs in the months immediately following the copulation.

\section{Size of offspring, time between copulation and laying and female age for mating}

Mated females deposited eggs within 20.0 days $(\mathrm{N}=18$ egg sacs, extreme values $=10$ and 31$)$ and after other 40.1 days the spiderlings emerged ( $N=46$ egg sacs and extreme values $=20$ and 59 days). The second egg sac appeared shortly before emergence of the first progeny. Average time between two consecutive layings in the fertile period ( $\mathrm{N}=18 \mathrm{egg}$ sacs) was 39.2 days (extreme values of 14 and 82 ). The period between consecutive spiderlings emergencies ( $N=15$ egg sacs) was 47.8 days (extreme values of 31 and 69). All these extreme values were not reckoned in the average calculation. The size of offspring revealed a tendency to reduction as the intervals between female maturity and mating were longer (Fig. 1). This result was obtained from 20 females born in laboratory and coupled 95 days after becoming adults. Thus, the first mating at a time that almost exceeded twice the female's adult age, resulted in fewer individuals $\left(X^{2}=5.08,13\right.$ d.f., $\left.p>0.01\right)$.

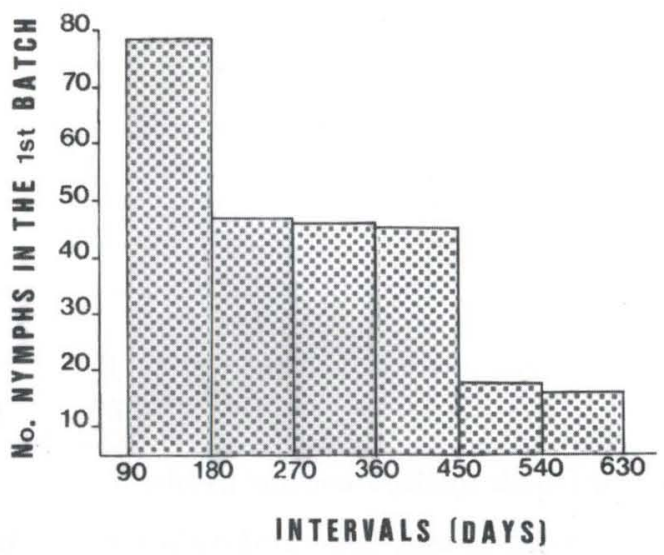

Fig. 1. Size of Loxosceles gaucho offspring according to female age. The intervals comprise the time between maturity and first mating of the females.

\section{Sex identification, number of instars and sex ratio}

At each subsequent nymphal stage, sex was checked by the examination of the palpi through the direct observation and stereomicroscopic examination on each individual. In a population at instar VI, up to $96 \%$ of the individuals could have their sex identified, and this was unaltered when either examination method was employed. Only in two L. gaucho males at the VI and VII instars, the palpi did not attain normal adult differentiation in the course of 539 days, being longer than the species average number to reach maturity. Therefore, the instar VI was the minimum 
age for these spiders' maturity, as the males and the females at this stage responded to mating and brought about offspring. Before instar VI, no male had mature palpi and no female responded to the male courtship, either. Continuous registration of the moulting process during spiders lifetime in laboratory permitted the establishment of the total number of instars, once this species do not moult after having attained adulthood. Although variable even within the same population, the majority, among both sexes, exhibited seven to eight instars, performing six to seven nymphal ecdyses (Fig. 2). The average sex ratio was 1.0:1.7 (male:female) and referred to 14 populations. The remaining five populations presented the greatest variations including up to 1 male: 7 or 4 females and in two cases 1.2 males: 1 female; not reckoned in the average calculation. The female and the male data are indicated on table II. Sex ratios were observed for populations with different survival percentages, such as, $29.4 \%, 38 \%, 75 \%$ and $78 \%$.

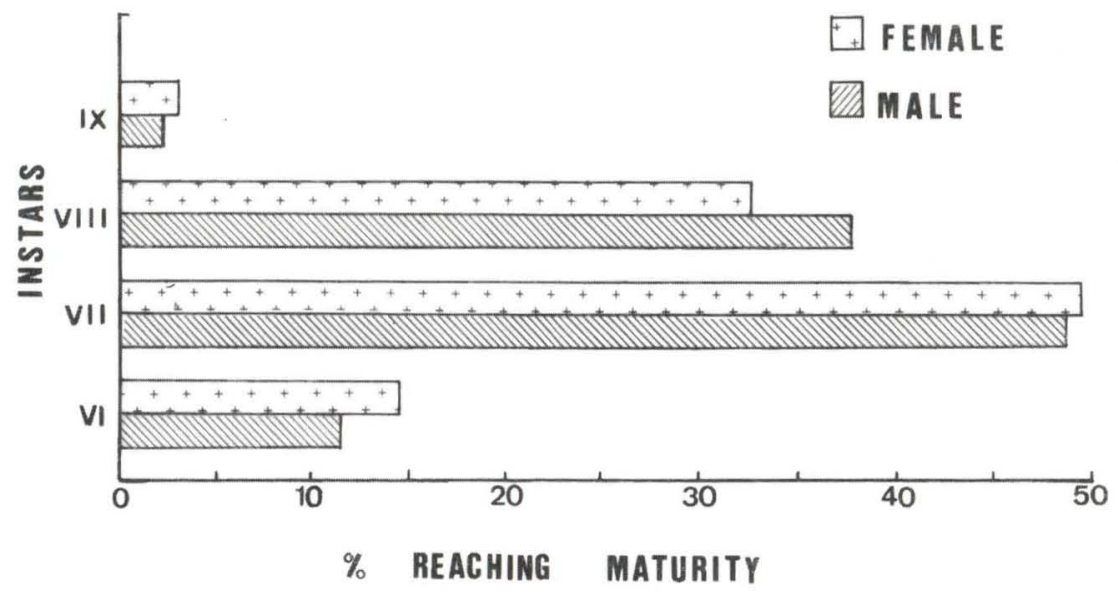

Fig. 2. Percentage of males and females of Loxosceles gaucho reaching maturity on a range of nymphal instars.

\section{Maturation time}

The maturation time for males and females includes data of individuals with a long life in laboratory (Tab. I). Males belonging to different populations had five to seven moults until attaining adulthood in a same period of 330 days. The same is valid for females of distinct populations. About $91.1 \%$ of the observed males became adult in an average of 15 to 17 months and about $86.8 \%$ of the females in an average of 15.5 to 18 months (Fig. 3). Extreme average values were: 356.5 and 518.7 days for males and 371.8 and 610.5 days for females concerning to five and eight moults respectively (Tab. I). The length of time presented a great variability, but total average time until adulthood was not significantly different between 483.3 days for males and 486.9 days for females $\left(X^{2}=27.18,17\right.$ d.f., $p>0.01, N=170$ males and 204 females). In the earlier nymphal period of $L$. gaucho's life, the time between two successive moults was not significantly different among males and females: 
$X^{2=} 24.52 ; 17$ d.f., $\mathrm{p}>0.01$ at instar II; $X^{2=} 27.82,17$ d.f., $\mathrm{p}>0.01$ at instar III; $X^{2=} 21.98,17$ d.f., $p>0.01$ at instar IV; $X^{2}=13.57,17$ d.f., $p>0.01$ at instar V (Fig. 4).

Table I. Maturation time for 18 populations of Loxosceles gaucho in relation to the number of moults.

\begin{tabular}{|c|c|c|c|c|c|c|c|c|c|c|c|c|c|c|c|c|c|c|}
\hline \multirow{2}{*}{$\begin{array}{l}\text { \# of moults } \\
\text { to adulthood }\end{array}$} & \multicolumn{18}{|c|}{ Male populations } \\
\hline & $1^{\text {st }}$ & $2^{\text {nd }}$ & $3^{\text {rd }}$ & $4^{\text {th }}$ & $5^{\text {th }}$ & $6^{\text {th }}$ & $7^{\text {th }}$ & $8^{\text {th }}$ & $9^{\text {th }}$ & $10^{\text {th }}$ & $11^{\text {th }}$ & $12^{\text {th }}$ & $13^{\text {th }}$ & $14^{\text {th }}$ & $15^{\text {th }}$ & $16^{\text {th }}$ & $17^{\text {th }}$ & $18^{\text {th }}$ \\
\hline 5 & 330.0 & 313.0 & 345.0 & 286.0 & 366.0 & 384.0 & - & 365.0 & - & - & - & - & - & - & - & - & 463.0 & - \\
\hline 6 & 372.9 & 316.3 & 309.2 & 356.7 & 429.5 & 400.5 & 5480.0 & 579.0 & - & - & 598.0 & 0467.0 & 512.0 & - & 507.5 & 460.5 & 455.0 & 442.0 \\
\hline 7 & 496.0 & 300.9 & 330.0 & 473.0 & 495.0 & 668.3 & 3557.9 & - & 556.0 & 543.5 & $5-$ & 555.7 & 7587.3 & 3549.0 & 578.4 & 510.5 & 498.1 & 458.0 \\
\hline 8 & - & - & - & 472.0 & 514.0 & - & - & - & - & - & - & - & 570.0 & - & - & - & - & - \\
\hline Mean & 399.6 & 308.1 & 313.8 & 368.9 & 466.4 & 531.7 & 7534.5 & 472.0 & 556.0 & 573.5 & 5598.0 & 0520.2 & 2570.4 & 4549.0 & 550.1 & 498.0 & 473.0 & 446.6 \\
\hline \multirow[t]{2}{*}{$N=170$} & 10 & 16 & 20 & 17 & 13 & 6 & 10 & 2 & 2 & 4 & 1 & 5 & 11 & 1 & 15 & 8 & 22 & 7 \\
\hline & \multicolumn{18}{|c|}{ Female populations } \\
\hline 5 & 289.0 & 286.0 & - & - & 338.0 & 413.0 & 0379.5 & 474.0 & - & - & 388.0 & 0404.0 & 378.0 & - & - & - & 388.0 & 352.7 \\
\hline 6 & 378.2 & 295.6 & 347.9 & 356.2 & 447.0 & 548.0 & 0533.5 & 533.0 & 536.5 & $5-$ & 532.0 & 0 494.2 & 2512.0 & 468.7 & 516.9 & 438.4 & 465.8 & 408.5 \\
\hline 7 & 379.0 & 383.2 & 418.6 & 403.0 & 525.0 & 653.0 & 0539.9 & 570.3 & 564.2 & 577.7 & 7604.7 & 7508.3 & 3583.5 & 506.0 & 563.7 & 579.5 & 670.4 & 557.0 \\
\hline 8 & - & - & 547.0 & - & 584.0 & - & - & - & - & - & - & 561.0 & 701.0 & 577.0 & 693.0 & - & - & - \\
\hline Mean & 348.7 & 317.0 & 382.6 & 356.2 & 485.1 & 568.0 & D 512.1 & 543.6 & 555.0 & 577.7 & 7572.5 & 5498.6 & 583.8 & 493.0 & 552.9 & 464.1 & 524.9 & 428.7 \\
\hline$N=204$ & 12 & 15 & 20 & 12 & 13 & 9 & 12 & 5 & 6 & 3 & 9 & 17 & 12 & 6 & 15 & 11 & 16 & 11 \\
\hline
\end{tabular}

*. $X^{2}=27.6$, d.f. $17, p>0.01 ;(\mathrm{N})$ number of individuals.

Table II. Distribution of the average Intermoult rates on the development of Loxosceles gaucho.

\begin{tabular}{|c|c|c|c|c|c|c|c|c|c|c|c|}
\hline \multirow{2}{*}{\multicolumn{2}{|c|}{$\begin{array}{c}\text { Populations } \\
\text { (Total number of } \\
\text { male:female) }\end{array}$}} & \multicolumn{10}{|c|}{ Mean intermoult rates (days) * } \\
\hline & & \multicolumn{2}{|c|}{$\begin{array}{l}\text { Adults entering } \\
5 \text { moults }\end{array}$} & \multicolumn{2}{|c|}{$\begin{array}{l}\text { Adults entering } \\
6 \text { moults }\end{array}$} & \multicolumn{2}{|c|}{$\begin{array}{l}\text { Adults entering } \\
7 \text { moults }\end{array}$} & \multicolumn{2}{|c|}{$\begin{array}{l}\text { Adults entering } \\
8 \text { moults }\end{array}$} & \multicolumn{2}{|c|}{$\begin{array}{l}\text { Mean intermoults } \\
\text { (rates for each } \\
\text { population) }\end{array}$} \\
\hline & & Male & Female & Male & Female & Male & Female & Male & Female & Male & Female \\
\hline $1^{\text {st }}$ & $(12: 13)$ & 62 & 65 & 68 & 69 & 77 & 57 & - & - & 67.0 & 67.1 \\
\hline $2^{\text {nd }}$ & $(18: 15)$ & 61 & 56 & 56 & 56 & 52 & 58 & - & - & 55.0 & 56.0 \\
\hline $3^{\text {rd }}$ & $(24: 25)$ & 68 & - & 57 & 63 & 61 & 66 & - & 74 & 59.0 & 64.0 \\
\hline $4^{\text {th }}$ & $(16: 13)$ & 64 & 74 & 65 & 65 & 73 & - & 63 & - & 65.6 & 65.8 \\
\hline $5^{\text {th }}$ & $(14: 16)$ & 78 & 83 & 80 & 85 & 77 & 83 & 69 & 79 & 78.0 & 83.0 \\
\hline $6^{\text {th }}$ & $(17: 12)$ & 87 & 89 & 78 & 102 & 106 & 104 & - & - & 91.0 & 99.0 \\
\hline $7^{\text {th }}$ & $(10: 13)$ & - & 88 & 90 & 93 & 87 & 83 & - & - & 88.0 & 88.0 \\
\hline $8^{\text {th }}$ & $(2: 5)$ & 75 & 109 & 91 & 99 & - & 87 & - & - & 83.0 & 95.0 \\
\hline $9^{\text {th }}$ & $(2: 6)$ & - & - & 78 & 85 & - & 83 & - & - & 78.0 & 88.0 \\
\hline $10^{\text {th }}$ & $(3: 8)$ & - & - & 92 & 90 & 80 & 81 & - & - & 84.0 & 84.0 \\
\hline $11^{\text {th }}$ & $(2: 9)$ & - & 80 & 101 & - & 98 & 93 & - & - & 101.0 & 92.0 \\
\hline $12^{\text {th }}$ & $(6: 18)$ & - & 90 & 86 & 90 & 85 & 78 & - & 74 & 86.0 & 84.0 \\
\hline $13^{\text {th }}$ & $(12: 14)$ & - & 84 & 94 & 88 & 91 & 90 & 76 & 95 & 89.0 & 90.0 \\
\hline $14^{\text {th }}$ & $(1: 7)$ & - & 71 & - & 84 & 84 & 78 & - & 77 & 84.0 & 81.0 \\
\hline $15^{\text {th }}$ & $(15: 17)$ & - & 74 & 92 & 95 & 86 & 84 & - & 96 & 88.0 & 90.0 \\
\hline $16^{\text {th }}$ & $(9: 12)$ & 69 & 84 & 78 & 74 & 72 & 84 & - & - & 73.0 & 76.0 \\
\hline $17^{\text {th }}$ & $(22: 29)$ & 77 & 71 & 84 & 78 & 69 & 102 & - & - & 77.0 & 82.6 \\
\hline $18^{\text {th }}$ & $(8: 6)$ & 82 & 79 & 70 & 81 & 79 & 78 & - & - & 73.0 & 79.0 \\
\hline \multicolumn{11}{|c|}{ Intermoults rates } & - \\
\hline
\end{tabular}

*. Intermoults rate $=$ sum total of days intermoult intervals of each individual divided by the number of moults; $X^{2}=3.08$, d.f. $17, p>0.01$. 


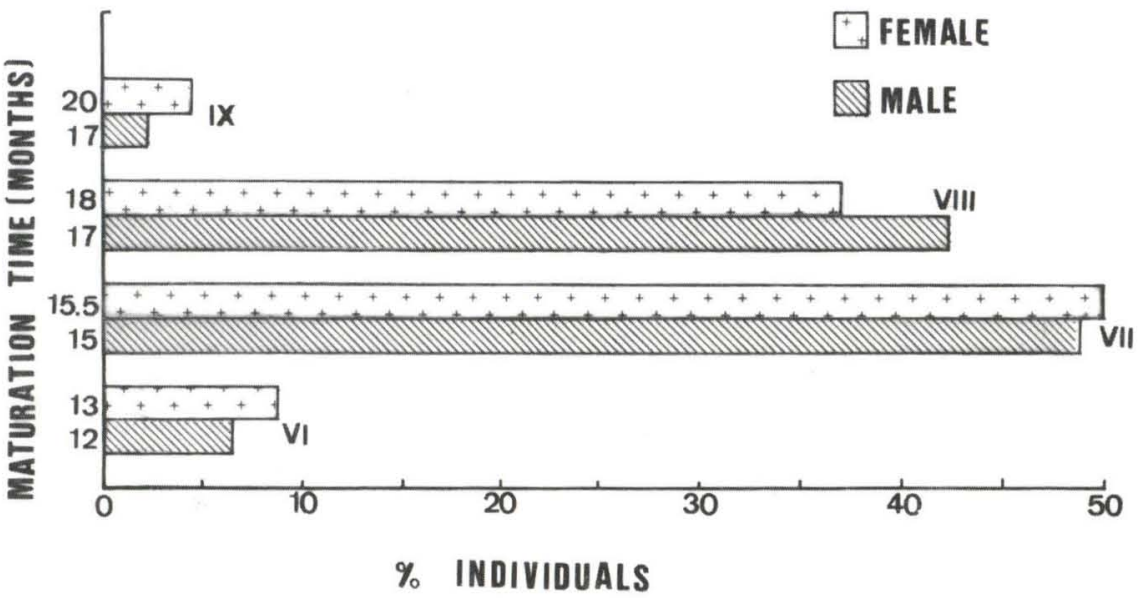

Fig. 3. Distribution of average age (months) until maturity for 18 populations of Loxosceles gaucho.

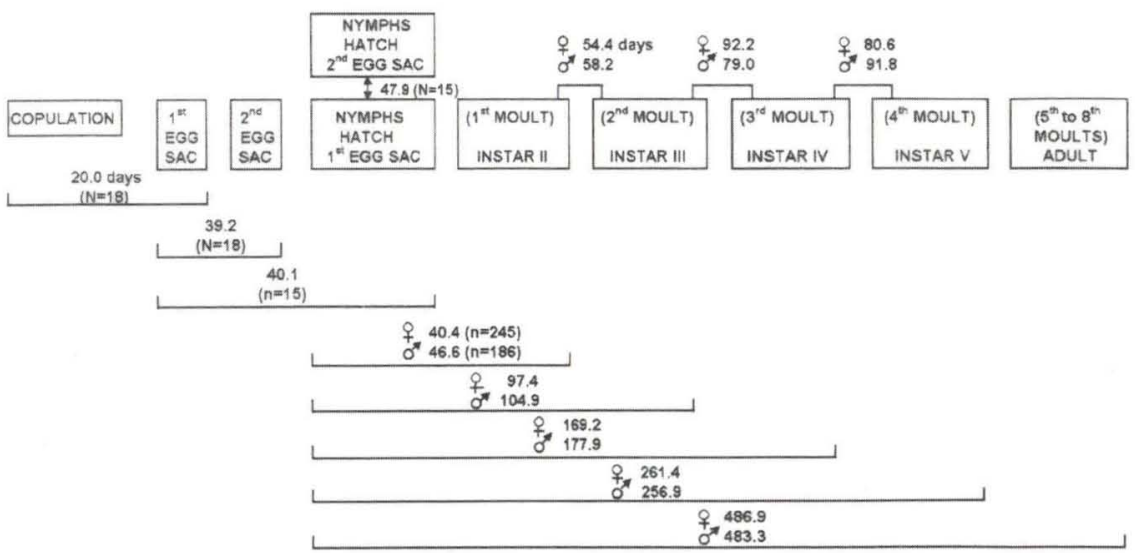

Fig. 4. Summary of life history data for the brown spider, Loxosceles gaucho reared in laboratory. (N) Number of egg sacs, ( $n$ ) number of individuals. 


\section{Intermoult intervals}

The total sum of intermoult intervals of each individual's life cycle divided by the number of moults resulted in an average number of days which enabled a value that makes the comparison within intra and interpopulations possible. Two females, originated in the same population and with identical lifetime, presented equivalent initial intervals but the times were inverted between the $3^{\text {rd }} / 4^{\text {th }}$ and the $5^{\text {th }} / 6^{\text {th }}$ moults, in such a way that for one female the first interval was 76 days and the second 104 days whilst for the other female it lasted 184 and 30 days, respectively. The average intermoult rates after the $4^{\text {th }}$ ecdysis for males and females belonging to 18 populations are presented in table II. The $X^{2}$ test was applied to find possible differences between intermoult rates of males and females from several populations. Average intermoult rates among males and females from interpopulations were not significantly different $\left(X^{2}=3.08,17\right.$ d.f., $\left.p>0.01\right)$.

\section{DISCUSSION}

The observed average number of fertile eggs per cocoon for gaucho was according to what Bücherl (in BÜCHERL \& BUCKLEY 1971) published for the Loxosceles genus, and these conclusions probably apply to the South American species. On the other hand, 12 to 15 eggs per egg sac earlier registered for L. gaucho by BÜCHERL (1961) probably resulted from laying of the senescent period in females. As found for L. laeta (GALIANo 1967), L. gaucho egg sacs were consecutive but not simultaneous and both species did not show any reaction when their egg sac was removed. Although laboratory females usually stayed away from the egg sacs, this habit was never observed in their own habitat. The L. gaucho's female care was usually limited to attaching the cocoon in a inner cage's cover and sitting over it. It was not needed for the emergence of the spiderlings, since they successfully emerged from egg sacs isolated from the female, as it was also observed for L. reclusa Gertsch \& Mulaik (HORNER \& STEWART 1967) too.

It is usually agreed that Araneae follow a pattern in which a reduction of viable egg number per successive egg sac occurs. Indeed, as observed by AUSTIN (1984 in NENTWIG 1987) the size of offspring is regulated by diverse factors and clearly suffers the influence of the female's fertility period and food availability. But the last egg sac which precedes the female's final fertility period always results in small offspring. We agree with HORNER \& STEWART (1967) who indicated this was perhaps due to gradual loss of viability or adequate numbers of sperm stored in the spermathecae. Regarding to the number of cocoons per female we noted that in specific environments, such as in stacks of tiles, where these spiders tend to cluster together, egg sacs can be observed practically all through the year, but adult time activity is still unknown. Compared to the spiders North American data, such as for $L$. reclusa, the fertility of $L$. gaucho was superior to the number of eggs per egg sac, and to the number of egg sacs produced by a female in a year. The average of 61,3 eggs per egg sac for L. gaucho, was the maximum eggs for L. reclusa as well. According HORNER \& STEWART (1967) they produced an average of 1.6 egg sac in a given year: three was the maximum number of egg sacs per female. Nevertheless, 
WEEMS \& WHITCOMB (1975) registered up to five egg sacs and 50 eggs per egg sac for this species.

An interesting aspect of mass rearing of venomous spiders in captivity is the possibility to adequately manage the populations, establishing the desired quantity of females and males. But for $L$. gaucho and probably for all Loxosceles species, sex differentiation by the pedipalpi development takes into account the long time. By measuring the palpi of L. laeta, Galiano (1967) also found the instar VI was the earlier age for accurate recognition of the sexes. It is suitable for sex distinction but it is not for the diagnosis of maturity in haplogyne female. The earlier instar where $L$. gaucho became adult was properly established by mating the females and checking their offspring besides observing their complete life cycle in laboratory. By these methods, it was clear that instar VI was earliest when females L. gaucho spiders became adult and it was variable between females of different populations. Compared to L. laeta (GALIANO 1967), L. gaucho differed because its moult range was from five to eight while $L$. laeta had from nine to 12 moults. Our data are in accordance with what LOWRIE (1987) found only for L. laeta females kept on mixed diet. Besides the contrast between these data, we considered that the rearing conditions, including the frequency of feeding and type of prey, could be responsible for the differences. For L. reclusa, HORNER \& STEWART (1967) pointed out that this species may go through a variable number of instars (seven or eight) depending on temperatures during development. Temperature, humidity and diversity in food supply may contribute to variation in the number of instars (SHAEFER in NENTWIG 1987).

Another fact in gaucho development was the proportionally equal number of moults verified for both males and females, allowing us to consider that this species did not play the rule of Araneae in which males depend on fewer moults than females, due to their smaller size, as stated among others, by FoELIX (1982: 172). According to LEVY's (1970) classification, L. gaucho belongs to the group of spiders where sexes undergo the same number of moults and mature in approximately the same length of time. Therefore, the female number of moults to reach maturity does not show any influence in their brood size. So, the reductions of their brood size was only a function of the lapse of time between their maturity and first mating.

A similar number of females and males occurred in L. gaucho's populations, as shown by GERTSCH (1967). The sex ratio 1:6 (male:female) as found in nature by BÜCHERL (1961), probably reflects the frequent condition in L. gaucho, in which males and nymphs are more active individuals than sedentary females on their cocoons. Then the females may have been overestimated because the males always run away in response to the disturbance of their habitat. In this situation, the surplus of females has not certainly been explained by the fact that males have a shorter life span. HORNER \& STEWART (1967) observed for L. reclusa a sex ratio of 1:2 (male:female) in a field collection and a sex ratio of 1:2 (male:female) for spiders laboratory-reared.

In spite of the identical conditions for all the spiderlings, great variability in the intermoult intervals were observed. According to SHAEFER (in NENTWIG 1987), 
the length of the intermoult cycle is modulated by temperature, hunger and other environmental influences. He also stated that the outstanding feature of spider development is its variability. We consider that the averages deduced between two successive moults, at least after the instar III, are not relevant for a general idea on spider life cycles. In our opinion, it makes no sense to obtain averages because they do not characterize the lifetime lengths of this species. It can be concluded that a higher number of moults correspond to somewhat shorter intervals and that a lower number of moults is compensated by longer intermoult periods. Therefore, the choice of an "intermoult rate" which combines the number of moults until maturity and the number of days to reach it, reveals a pattern of these spiders' life cycle and explains more than the average numbers traditionally obtained.

ACKNOWLEDGEMENTS. This work was supported in part by Fundação para o Desenvolvimento da UNESP (FUNDUNESP). We are grateful to Mrs. Nedy A. Andrés and Mr. Pedro Evangelista for their care in looking after the spiders in the laboratory and for their help during collections.

\section{REFERENCES}

BÜCHERL, W. 1961. Aranhas do gênero Loxosceles e loxoscelismo na América. Ciência e Cultura 13: 213-224.

BÜCHERL, W. \& E.E. BUCKLEY. 1971. Venomous animals and their venoms. vol. III. Venomous Invertebrates. New York, Academic Press, XXII+537p.

FoELIX, R.F. 1982. Biology of Spiders. Cambridge, Harvard Press, VI+306p.

GALIANO, M.E. 1967. Ciclo biológico y desarollo de Loxosceles laeta (Nicolet, 1849). Acta Zool. Lilloana 23: 432-464.

Galiano, M.E.\& M. HALL. 1973. Datos adicionales sobre el ciclo vital de Loxosceles laeta. Physis 32: 277-288.

GeRTSCH, W.J. 1967. The spider genus Loxosceles in South America (Araneae, Scytodidae). Bull. Amer. Mus. Nat. Hist. 136: 117-174.

HoRnER, N.V. \& K.W. STEWART. 1967. Life History of the Brown Spider, Loxosceles reclusa Gertsch and Mulaik. Texas Jour. Sci. 19 (4): 333-347.

LEvY, G. 1970. The life cycle of Thomisus onustus (Thomisidae: Araneae) and outlines for the classification of the life histories of spiders. Jour. Zool., London, 160: $523-536$.

LOWRIE, D.C. 1987. Effects of diet on the development of Loxosceles laeta (Nicolet) (Araneae:Loxoscelidae). Jour. Arachnol. 15: 303-308.

NENTWIG, W. 1987. Ecophysiology of spiders. Berlin,Springer-Verlag, IX+488p. VACHON, M. 1957. Contribuition à l'étude du developpment postembryonnaire des araigneés. Premiére note. Généralités et nomenclature des stades. Bull. Soc. Zool. France 82: 337-354.

WeEms, H.V. \& W.H. Whitcomb. 1975. The Brown Recluse spider, Loxosceles reclusa Gertsch and Mulaik (Araneae: Loxoscelidae). Fla. Dept. Agr. \& Consumer Serv. 158: 1-2.

Recebido em 17.X.1996; aceito em 10.IX.1997

Revta bras. Zool. 14 (3): 697 - 706, 1997 